OPEN ACCESS

Edited by: Andrea Chini,

National Center for Biotechnology (CNB), Spain

Reviewed by: John Mansfield, Imperial College London, United Kingdom

Annalisa Polverari,

University of Verona, Italy

*Correspondence: Cayo Ramos crr@uma.es Jesús Murillo jesus.murillo@unavarra.es

Specialty section: This article was submitted to Plant Pathogen Interactions,

a section of the journal

Frontiers in Plant Science

Received: 30 June 2020 Accepted: 07 August 2020 Published: 21 August 2020

Citation: Añorga M, Pintado A, Ramos C, De Diego N, Ugena L, Novák O and Murillo J (2020) Genes ptz and idi, Coding for Cytokinin Biosynthesis Enzymes, Are Essential for

Tumorigenesis and In Planta Growth by $P$. syringae $p v$. savastanoi NCPPB 3335. Front. Plant Sci. 11:1294. doi: 10.3389/fpls.2020.01294

\section{Genes ptz and idi, Coding for Cytokinin Biosynthesis Enzymes, Are Essential for Tumorigenesis and In Planta Growth by $P$. syringae pv. savastanoi NCPPB 3335}

\author{
Maite Añorga ${ }^{1}$, Adrián Pintado ${ }^{2,3}$, Cayo Ramos $^{2,3^{*}}$, Nuria De Diego ${ }^{4}$, Lydia Ugena ${ }^{4}$, \\ Ondřej Novák ${ }^{5,6}$ and Jesús Murillo ${ }^{1 *}$
}

${ }^{1}$ Institute for Multidisciplinary Research in Applied Biology, Universidad Pública de Navarra, Mutilva Baja, Spain, ${ }^{2}$ Área de Genética, Facultad de Ciencias, Universidad de Málaga, Málaga, Spain, ${ }^{3}$ Instituto de Hortofruticultura Subtropical y Mediterránea "La Mayora", Consejo Superior de Investigaciones Científicas (IHSM-UMA-CSIC), Málaga, Spain, ${ }^{4}$ Department of Chemical Biology and Genetics, Centre of the Region Haná for Biotechnological and Agricultural Research, Faculty of Science, Palacký University, Olomouc, Czechia, ${ }^{5}$ Laboratory of Growth Regulators, Faculty of Science, Palacký University, Olomouc, Czechia, ${ }^{6}$ Institute of Experimental Botany, Czech Academy of Sciences, Olomouc, Czechia

The phytopathogenic bacterium Pseudomonas syringae pv. savastanoi elicits aerial tumors on olive plants and is also able to synthesize large amounts of auxins and cytokinins. The auxin indoleacetic acid was shown to be required for tumorigenesis, but there is only correlational evidence suggesting a role for cytokinins. The model strain NCPPB 3335 contains two plasmid-borne genes coding for cytokinin biosynthesis enzymes: ptz, for an isopentenyl transferase and idi, for an isopentenyl-diphosphate delta-isomerase. Phylogenetic analyses showed that carriage of ptz and idi is not strictly associated with tumorigenic bacteria, that both genes were linked when first acquired by $P$. syringae, and that a different allele of ptz has been independently acquired by $P$. syringae pv. savastanoi and closely related bacteria. We generated mutant derivatives of NCPPB 3335 cured of virulence plasmids or with site-specific deletions of genes ptz and/or idi and evaluated their virulence in lignified and micropropagated olive plants. Strains lacking $p t z$, idi, or both produced tumors with average volumes up to 29 times smaller and reached populations up to two orders of magnitude lower than those induced by strain NCPPB 3335; these phenotypes reverted by complementation with the cloned genes. Trans-zeatin was the most abundant cytokinin in culture filtrates of NCPPB 3335. Deletion of gene ptz abolished biosynthesis of trans-zeatin and dihydrozeatin, whereas a reduced but significant amount of isopentenyladenine was still detected in the medium, suggesting the existence of other genes contributing to cytokinin biosynthesis in $P$. syringae. Conversely, extracts from strains lacking gene idi contained significantly higher amounts of trans-zeatin than extracts from the wild-type strain but similar amounts of the other cytokinins. This suggests that Idi might promote tumorigenesis by ensuring the biosynthesis of the most active cytokinin forms, their correct balance in planta, or by 
regulating the expression of other virulence genes. Therefore, gene ptz, but not gene idi, is essential for the biosynthesis of high amounts of cytokinins in culture; however, both ptz and idi are individually essential for the adequate development of tumors on olive plants by Psv NCPPB 3335.

Keywords: Pseudomonas savastanoi pv. savastanoi, olive knot, tumor, pathogenicity, virulence genes, virulence plasmids, indoleacetic acid, phytohormones

\section{INTRODUCTION}

Plant defense against offenders is expensive, requiring an investment that could otherwise be used for reproduction. Plants have therefore evolved resource management mechanisms diverting energy to either growth or defense, depending on environmental conditions: the 'growth-defense trade-off' phenomenon (Huot et al., 2014). These adaptive responses are largely controlled by a delicate balance of phytohormones, and so it is not surprising that phytopathogens also evolved a myriad of sophisticated strategies to interfere with this balance to facilitate pathogen colonization and disease development (Denancé et al., 2013; Ma and Ma, 2016).

The gammaproteobacterium Pseudomonas syringae is a complex of taxonomically diverse species that cause economically relevant diseases in many annual and woody plants (Lamichhane et al., 2014; Lamichhane et al., 2015). This bacterial complex comprises at least 13 phylogroups (PGs), traditionally distributed into more than 60 pathovars, which are infrasubspecific groups defined by their ability to cause distinctive disease syndromes in a set of defined plant hosts (Young, 2010). Pathogenicity and virulence are generally dependent on a type III secretion system (T3SS), delivering pathovar- and strain-specific suites of effector proteins into the cell cytoplasm, mainly to suppress plant defense responses (Cunnac et al., 2009; Dillon et al., 2019a). Nevertheless, $P$. syringae strains produce a diversity of other molecules that increase virulence or microbial fitness, among which phytotoxins and hormones are paramount for their relevance and wide distribution (Glickmann et al., 1998; Bender et al., 1999; Cunnac et al., 2009; Caballo-Ponce et al., 2017a; Dillon et al., 2019b). P. syringae commonly induces spots and blights of leaves, stems and fruits, with bacterial cankers and blights as the most common diseases of woody plants (Agrios, 2005; Lamichhane et al., 2014). Another frequent type of symptoms induced in woody hosts are galls or tumors (Lamichhane et al., 2014; Caballo-Ponce et al., 2017a), which are exclusively caused by $P$. syringae pathovars cerasicola, daphniphylli, dendropanacis, myricae, nerii, retacarpa, rhaphiolepidis, and savastanoi plus $P$. meliae and $P$. tremae, all belonging to PG3 (also called genomospecies 2; syn. P. amygdali) (Gardan et al., 1999; Gomila et al., 2017).

Abbreviations: CKs, cytokinins; cZ, cis-zeatin; DHZ, dihydrozeatin; DHZR, dihydrozeatin riboside; DMAPP, dimethylallyldiphosphate; HMBDP, hydroxymethylbutenyl diphosphate; $i d i$, isopentenyl-diphosphate delta-isomerase gene (locus_tag PSPSV_C0024); IAA, indoleacetic acid; iP, isopentenyladenine; iPR, isopentenyl adenosine; iPRMP, isopentenyladenosine $5^{\prime}$-monophosphate; MEP, methylerythritol phosphate pathway; MVA, mevalonate pathway; ptz, isopentenyl transferase gene (locus_tag PSPSV_A0024); tZ, trans-zeatin; tZR, trans-zeatin riboside; ZRMP, trans-zeatin riboside 5'-monophosphate.
P. syringae pv. savastanoi (Psv) causes tumors in olive (Olea europaea) and is a prominent research model for woody pathosystems (Ramos et al., 2012; Caballo-Ponce et al., 2017a). As occurs with pathovars infecting annual plants, pathogenicity of Psv is dependent on the functionality of a type III secretion system (Sisto et al., 2004; Pérez-Martínez et al., 2010). Additionally, the virulence of Psv is modulated by several other factors, including $\mathrm{Na}^{+} / \mathrm{Ca}^{2+}$ exchange (Moretti et al., 2019), quorum sensing, metabolism of phenolics, c-di-GMP metabolism, and, importantly, the production of the phytohormones indoleacetic acid (IAA) and cytokinins (CKs) (Caballo-Ponce et al., 2017a). The biosynthesis of high levels of IAA in $P$. syringae takes place through the indole-3-acetamide pathway and requires the iaaMH operon (Comai and Kosuge, 1980; Yamada et al., 1985; Aragón et al., 2014), which has a rather restricted distribution within $P$. syringae (Glickmann et al., 1998; Ramos et al., 2012). Genes iaaMH have a large and complex contribution to virulence and are required for the elicitation of tumors on olive plants; they increase in planta competitiveness and also affect the expression of other virulencerelated genes (Silverstone et al., 1993; Aragón et al., 2014).

Natural CKs are substituted adenine molecules carrying on the $N^{6}$ position an aromatic or, more frequently, an isoprenoid-derived side chain (Sakakibara, 2006; Sakakibara, 2010). Biosynthesis of isoprenoid CKs can follow two possible pathways. One of the pathways is derived from tRNA degradation and leads to ciszeatin (cZ)-type CKs, which have not been detected in cultures of tumorigenic $P$. syringae pathovars. The second pathway derives from isopentenylation of free adenine nucleotides. This is initiated by the condensation of AMP with dimethylallyldiphosphate (DMAPP) or of hydroxylated derivatives of DMAPP such as hydroxymethylbutenyl diphosphate (HMBDP) and is catalyzed by the key enzyme, isopentenyl transferase (Figure 1). CKs synthesized through this pathway were detected in cultures of $P$. syringae pathovars savastanoi and nerii, the latter highly related to Psv and also producing tumors on oleander, as well as in $P$. amygdali. Diverse works report the detection in these bacteria of up to eight types of CKs (trans-zeatin (tZ), dihydrozeatin (DHZ), trans-zeatin riboside (tZR), dihydrozeatin riboside (DHZR), isopentenyl adenine (iP), isopentenyl adenosine (iPR), 1'-methylzeatin and ribosyl-1" methylzeatin), although there is considerable variability in the types and amount of CKs produced by different strains (Surico et al., 1975; Surico et al., 1985a; Evidente et al., 1986; MacDonald et al., 1986; Iacobellis et al., 1990; Morris et al., 1991; Marchi et al., 2011). A gene for isopentenyl transferase (gene $p t z$ ) has been cloned from Psv and shown to direct the biosynthesis of certain CKs in culture when expressed in E. coli (MacDonald et al., 1986; Powell and 


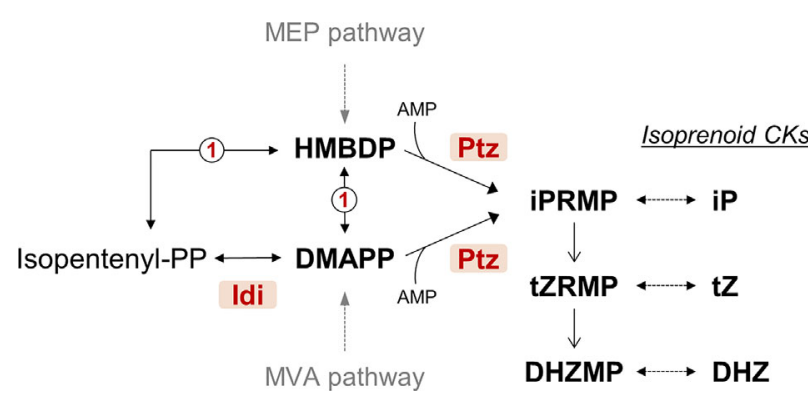

FIGURE 1 | Simplified predicted pathway for the biosynthesis of cytokinins by Pseudomonas syringae pv. savastanoi NCPPB 3335. CKs, cytokinins; $\mathrm{DHZMP}$, dihydrozeatin riboside monophosphate; $\mathrm{DHZ}$, dihydrozeatin; DMAPP, dimethylallyl diphosphate; Idi, isopentenyl-diphosphate deltaisomerase (locus_tag PSPSV_C0024); HMBDP, hydroxymethylbutenyl diphosphate; iP, isopentenyladenine; iPRMP, isopentenyladenosine 5' monophosphate; Ptz, isopentenyl transferase (locus_tag PSPSV_A0024); tZ, trans-zeatin; tZRMP, trans-zeatin riboside 5'-monophosphate. MEP and MVA are the methylerythritol phosphate and the mevalonate pathways, respectively. Enzyme marked as 1 in a circle is the predicted product of gene PSA3335_RS23935, annotated as 4-hydroxy-3-methylbut-2-enyl diphosphate reductase. Dotted arrows indicate more than one reaction step. The pathway is condensed from the Kyoto Encyclopedia of Genes and Genomes (KEGG) database and published pathways (Sakakibara, 2006; Sakakibara, 2010).

Morris, 1986). Gene idi (originally called ipt), coding for an isopentenyl-diphosphate delta-isomerase, has also been found in Psv (Bardaji et al., 2011). Its product is predicted to provide the substrate DMAPP for the Ptz enzyme (Figure 1), but its role in the biosynthesis of CKs has not been demonstrated.

Genes for biosynthesis of phytohormones by Psv and $P$. syringae pv. nerii are sometimes located in native plasmids, and hence, it was shown that plasmid curing can lead to a reduction in the size of tumors (MacDonald et al., 1986; Iacobellis et al., 1994; Pérez-Martínez et al., 2008; Bardaji et al., 2011). Nevertheless, plasmid curing could completely abolish or diminish CK production, indicating that more than one gene could participate in CK biosynthesis. Diverse studies have also found a positive association between the amount of CKs naturally produced by certain $P$. syringae strains and the size of knots induced in the plant host (Surico et al., 1985b; Cinelli et al., 2014; Schiff et al., 2019), although this is not always true, suggesting the existence of additional strain-specific genes contributing to virulence. Similarly, a strain of $P$. syringae pv. nerii was able to induce tumors of nearly wild-type size in oleander, despite being unable to synthesize CKs (Roberto and Kosuge, 1987). Therefore, and taking into account the plethora of virulence genes carried by native plasmids of the $P$. syringae complex (Vivian et al., 2001; Sundin, 2007), and that knock-out mutants of CKs-related genes have not yet been reported, these correlational studies do not clarify the impact of Psv-produced CKs in virulence.

The model strain Psv NCPPB 3335 carries genes $p t z$ and $i d i$ in plasmids pPsv48A and pPsv48C, respectively (Bardaji et al., 2011). In this work, we obtained a plasmidless derivative of
NCPPB 3335 as a tool for the identification of virulence genes and, together with the generation of site-directed mutants of genes $p t z$ and $i d i$, to evaluate the role of CKs in its pathogenicity in olive plants. We demonstrate that gene $p t z$ is essential, but not gene idi, for the biosynthesis of CKs in culture and that both genes and/or their products are required for the development of tumors by Psv NCPPB 3335.

\section{MATERIAL AND METHODS}

\section{Bacterial Strains and Growth Conditions}

Bacterial strains and plasmids are detailed in Supplementary Table S1. Strains were routinely propagated at $25^{\circ} \mathrm{C}$ or $37^{\circ} \mathrm{C}$, for P. syringae and E. coli, respectively, using LB (Sambrook et al., 1989) or nutrient agar (NA; Oxoid), which was supplemented with $5 \% \mathrm{w} / \mathrm{v}$ of sucrose (medium SNA) for counter selection of clones containing Tn5-GDYN1. When necessary, media were supplemented with the following antibiotics (final concentrations in $\mu \mathrm{g} \mathrm{ml}^{-1}$ for Pseudomonas/E. coli): ampicillin (Amp) 300/100, gentamicin (Gm) 12.5, kanamycin (Km) 7/50, nitrofurantoin (Nf) 100, spectinomycin (Spc) 25, tetracycline (Tc) 12.5 .

\section{Molecular Techniques and Bioinformatics}

General molecular biology techniques were followed (Sambrook et al., 1989). Plasmid DNA from Pseudomonas was purified by a rapid alkaline lysis (Zhou et al., 1990); plasmids from E. coli were purified using a boiling lysis method (Holmes and Quigley, 1981) or a commercial kit (Illustra plasmid Prep Mini Spin Kit, GE Healthcare). Undigested plasmids were separated in $0.8 \%$ agarose gels by electrophoresis (Sesma et al., 2000). Plasmids were transferred to $P$. syringae by electroporation (Choi et al., 2006).

PCR amplifications were done using standard (BIOTaq, Bioline, UK) or high-fidelity (PrimeStar HS, Takara Bio Inc., Japan) polymerase mixes and using primers listed in Supplementary Table S2. Amplicons were purified using the QIAquick PCR Purification Kit (QIAGEN) and cloned into vectors pJET1.2 (CloneJET PCR Cloning Kit; Thermo Scientific) or pGEM-T Easy (Promega). Genomic DNA was purified using the Jet Flex Extraction (Genomed; Löhne, Germany) kit. Sanger and whole genome sequencing using Illumina Myseq $2 \times 300$ were done by Macrogen Inc. (Amsterdam). Paired reads (coverage $60 \times$ ) from strain UPN912 $(\triangle \mathrm{ABC})$ were qualitatively assessed before de novo assembling with CLC Genomics Workbench (v 10.1.1) software (BioProject PRJNA638121). Sequences were visualized and manipulated using the Artemis and ACT software (Carver et al., 2008). Sequence comparisons were done using the Blast algorithms (Hubbard et al., 2008) and sequence alignments using the web servers for MultAlin (Corpet, 1988) or for EMBL-EBI tools (Chojnacki et al., 2017). Promoters were predicted using the online version of BProm (Softberry Inc., Mt. Kisco, NY; Solovyev and Salamov, 2011). Primers were designed with Primer3plus (Untergasser et al., 2012). Sequence alignments 
using Muscle, substitution model selection, phylogenetic analyses using the Maximum Likelihood method and branch support for the resulting trees by bootstrap analysis with 200 replicates were done using MEGA7 (Kumar et al., 2016).

Genes $p t z$ and $i d i$ were deleted from pPsv48A and pPsv48C, respectively, by marker exchange as follows. For $p t z$ we amplified DNA fragments of approximately $1 \mathrm{~kb}$, corresponding to the upstream and downstream flanking regions, with primers FAnewptz-F/R and FP_ptz-F18/FP_ptz-R-694 (Supplementary Table S2). Restriction sites for BamHI were included in the primers as described previously (Matas et al., 2014). The resulting product, consisting of upstream and downstream flanking regions separated by a BamHI restriction site, was cloned into pGEMT $\left(A m p^{\mathrm{R}}\right)$, and the $\mathrm{Km}$ resistance gene nptII from pGEM-TKmFRT-BamHI was cloned into the BamHI site. The plasmid was transferred to Psv NCPPB 3335 by electroporation (PérezMartínez et al., 2007), and transformants were selected on LB-Km plates. To select the allelic exchange, individual colonies were replicated onto LB-Amp plates and $\mathrm{Amp}^{\mathrm{R}}$ colonies were discarded. For gene idi, a 3,394 nt fragment spanning idi was amplified with primers mutipt_F/R (Supplementary Table S2) and cloned in pJET1.2. This construct was digested with SpeI and SmaI, liberating a $753 \mathrm{nt}$ fragment spanning all of gene idi plus the last $157 \mathrm{nt}$ of the previous CDS (PSPSV_C0023), ligated to the $\mathrm{Spc}^{\mathrm{R}}$ cassette amplified from $\mathrm{pHP} 45 \Omega$ and transferred to strain Psv48 $\triangle \mathrm{AB}$ and selecting on LB plus Spc. Clones were then serially transferred six consecutive times on LB to select, at the end of these transfers, a Spc ${ }^{\mathrm{R}}$ and $\mathrm{Amp}^{\mathrm{S}}$ clone, designated UPN1020 and containing pPsv48C $\Delta \mathrm{idi}$. The double mutant $p t z^{-i} i i^{-}$was constructed by transferring pPsv48C $\Delta$ idi to strain $\Delta$ ptz (UPN1028) and selecting on LB plus Spc and Km. All mutations were confirmed by PCR, Southern blot hybridization, and/or sequencing.

We constructed diverse plasmid for complementation in trans of the different mutants. The complete gene $p t z$, including the CDS, its promoter, and transcriptional terminator, was amplified by PCR as a 1,372 nt fragment using primers ExpptZ-F1/R2 (Supplementary Table S2) and cloned into pGEM-T. The fragment was then liberated with EcoRI and subcloned into pBBR1MCS-5; a clone containing ptz oriented for transcription from the constitutive $\mathrm{P}_{l a c}$ promoter of the vector was designated pIPMptz and selected for complementation analyses. Gene idi was amplified as a 1,117 nt fragment containing its predicted promoter, with primers iptC_F/R (1,117 nt) (Supplementary Table S2), or as a 2,311 nt fragment also containing the upstream CDS PSPSV_C0023, using primers iptC_R/iptSAM_F (Supplementary Table S2, Supplementary Figure S1) and cloned in pJET1.2. The inserts from the resulting constructions were liberated with BglII and individually cloned in the same site behind a T4 transcription terminator either in pME6031, for the $1.1 \mathrm{~kb}$ fragment and generating p31idi, or in pME6041, for the 2.3 $\mathrm{kb}$ fragment and generating p41idiSAM. The cloned 1,372 nt fragment of gene $p t z$ was amplified using primers ptz_F1/R1 (Supplementary Table S2), containing EcoRI adapters and cloned in pJET1.2. The EcoRI insert was liberated and cloned in p31idi to yield p31idiptz. All constructions were confirmed by sequencing.

\section{Curing of Plasmid pPsv48C to Yield $\triangle \mathrm{ABC}$}

Strain $\triangle \mathrm{AB}$ is cured of plasmids pPsv48A and pPsv48B but could not be cured of plasmid C (Bardaji et al., 2011). Therefore, this strain was mutagenized using transposon Tn5-GDYN1, essentially as described (Flores et al., 1993; Bardaji et al., 2011). This transposon carries a $s a c B$ gene conferring lethality in the presence of $5 \%$ sucrose and facilitates the selection of strains cured of native plasmids. One of the resulting mutants contained an insertion in pPsv48C after position 7,433, which was mapped as described (Bardaji et al., 2019) and was retained as strain UPN877. Plasmid pPsv48C carries two functional replicons (Bardaji et al., 2017) and three functional toxin-antitoxin modules that provide a very high stability (Bardaji et al., 2019). To facilitate curing of pPsv48C from UPN877, we functionally inactivated these toxin-antitoxin modules using the cloned antitoxins in plasmid pRK3C as described (Bardaji et al., 2019). For plasmid curing, overnight cultures of strain UPN877 (pRK3C) on LB were serially diluted and spread on SNA plates and incubated at $25^{\circ} \mathrm{C}$. The plasmid profile of well-separated colonies was then examined for the loss of pPsv48C::Tn5-GDYN1, and selection of the plasmidless strain $\triangle \mathrm{ABC}$ (UPN912) was done as described in Results.

\section{Quantification of Cytokinins}

Bacterial strains were grown overnight at $25^{\circ} \mathrm{C}$ with shaking $(200$ $\mathrm{rpm}$ ) in minimal A medium (in $\mathrm{g} / \mathrm{l}, \mathrm{K}_{2} \mathrm{HPO}_{4}, 10.5 ; \mathrm{KH}_{2} \mathrm{PO}_{4}, 4.5$; $\left(\mathrm{NH}_{4}\right)_{2} \mathrm{SO}_{4}, 1$; Na-citrate $\left.2 \mathrm{H}_{2} \mathrm{O}, 0.5 ; \mathrm{MgSO}_{4}, 0.12\right)($ Miller, 1992) supplemented with casamino acids and glucose at final concentration of 0.04 and $2 \mathrm{~g} / \mathrm{l}$, respectively (MacDonald et al., 1986). These were used to inoculate fresh minimal A medium to a $\mathrm{OD}_{600}$ of 0.1 and grown in the same conditions until reaching an $\mathrm{OD}_{600}$ of 0.6 , after approximately $12-14 \mathrm{~h}$. Cell-free culture supernatants were then collected by centrifugation and filtration through $2 \mu \mathrm{m}$ filters, and immediately frozen in liquid nitrogen until analyzed. For CK analyses we used three independent cultures, with two samples per culture, for each strain. A total of $200 \mu \mathrm{l}$ from each culture was collected twice and used as biological replicate for the cytokinin analysis, ending with 4 replicates per bacterial strain. Additionally, each replicate was extracted and quantified twice (technical replicate). Briefly, each culture was extracted using ice-cold modified Bieleski buffer (methanol/water/formic acid, 15/4/1, v/v/v) containing isotopelabelled CK internal standards $(0.5 \mathrm{pmol}$ of CK bases, ribosides, $\mathrm{N}$-glucosides, $1 \mathrm{pmol}$ of CK O-glucosides and nucleotides). The extract was then purified using two solid phase extraction columns, the octadecylsilica-based column (C18, $500 \mathrm{mg}$ of sorbent, Applied Separations) and the Oasis MCX column (30 $\mathrm{mg} / 1 \mathrm{ml}$, Waters), according to the method described by (Dobrev and Kaminek, 2002), including modifications described by Antoniadi et al. (2015).

\section{Pathogenicity Assays}

Micropropagated olive (Olea europaea) plantlets derived from a seed germinated in vitro, originally collected from a cv. Arbequina plant, were propagated and rooted in DKW medium (Driver and Kuniyuki, 1984) essentially as described 
(Rodríguez-Moreno et al., 2008). Rooted plantlets were transferred to DKW medium without hormones, and maintained in a growth chamber with a 16/8 h light/dark photoperiod, light intensity of $35 \mu$ moles $\mathrm{m}^{-2} \mathrm{~s}^{-1}$ and $25^{\circ} \mathrm{C}$ for at least two weeks; then, inoculations were done in sterility when plantlets were $60-80$ $\mathrm{mm}$ long and had 3-5 internodes. All strains used as inocula contained plasmid pLRM1-GFP $\left(\mathrm{Gm}^{\mathrm{R}}\right.$ ) (Rodríguez-Moreno et al., 2009), expressing GFP, to monitor tumor colonization by epifluorescence microscopy. Bacteria used for inoculations were scrapped off LB plates grown for 2 days, washed twice in $10 \mathrm{mM}$ $\mathrm{MgCl}_{2}$ and resuspended in this buffer to an $\mathrm{OD}_{600}$ of 0.5 (approximately $5 \times 10^{7} \mathrm{cfu} \mathrm{m}^{-1}$ ); then, $10^{3} \mathrm{cfu}$ were applied on a wound made with a scalpel on the stem on each plantlet. Plantlets were then maintained in the growth chamber in the same conditions as above and scored after 28 days using a stereoscopic fluorescence microscope (Leica MZ FLIII; Leica Microsystems, Wetzlar, Germany). Inoculations were done in a similar way for lignified olive plants (at least one-year-old) by depositing $10^{6} \mathrm{cfu}$ in a wound made in the stem, as described (Penyalver et al., 2006; Pérez-Martínez et al., 2007; Matas et al., 2012). Plants were maintained in a greenhouse under natural conditions, with an average temperature of $27^{\circ} \mathrm{C}$ and $58 \%$ of relative humidity, and symptoms were scored after 90 days using a high-resolution camera (Canon D600; Canon Inc., Tokyo, Japan).

Knot volumes developed on micropropagated olive plants were quantified using a 3D scanner and the MINIMAGICS 2.0 software. Weight and volume of tumors developed in one-year old lignified olive plants were obtained as described (Moretti et al., 2008; Hosni et al., 2011). To estimate bacterial populations, knots were crushed and homogenized in $10 \mathrm{mM} \mathrm{MgCl}_{2}$ and serial dilutions plated on LB supplemented with appropriate antibiotics for colony counting after two days of growth. Tumor weight and volume, as well as bacterial populations, were averaged from at least three independent replicates.

Means were compared using an analysis of variance (ANOVA) followed, when needed, by Duncan's multiple range test $(\mathrm{p}<0.05)$. We used software R Project 3.3.3 (R Core Team, 2017) to perform the statistics.

\section{RESULTS}

\section{Differential Distribution of Genes ptz and idi Among Tumorigenic Strains of $P$. syringae From PG3 (Genomospecies 2)}

Given their potential role in pathogenesis and the elicitation of tumors, we evaluated the distribution and conservation of genes $p t z$ and $i d i$ among the $P$. syringae complex.

BlastP comparisons identified homologs of the deduced products of genes ptz and idi in a variety of bacteria (Supplementary Figure S2). Phylogenetic analyses of these sequences immediately evidenced the separate evolution of these two genes before invading $P$. syringae because the closest relatives of Ptz and Idi are carried by phylogenetically different bacteria. The closest homologs of Ptz are in bacteria interacting with plants, including beneficial interactions, but those of Idi are not, being carried by bacteria exploiting other ecological niches. This dissimilar distribution of genes $p t z$ and idi suggests that $p t z$ is a gene widely required by bacteria for their successful interaction with plants, including the induction of tumors, but that gene idi is not.

Among bacteria of the $P$. syringae complex, we found genes for both Ptz and Idi in the tumorigenic pathovars cerasicola, myricae, nerii, retacarpa, and savastanoi and strain $\mathrm{Ph} 3$ from dipladenia (Mandevilla spp.) (Figure 2). Both genes were also present in $P$. syringae pv. photiniae, which is not reported to induce tumors but produces leaf spots and blights on cherry (Goto, 1983). Additionally, and although they are all reported to be tumorigenic bacteria (Ogimi, 1977; Ogimi et al., 1988a; Ogimi et al., 1988b; Ogimi et al., 1990; Ogimi et al., 1992), P. meliae only contained $p t z$, whereas $P$. syringae pvs. daphniphylli, dendropanacis, rhaphiolepidis, and tremae did not carry any of these two genes. The idi gene was highly conserved in all these strains, but we found two distinct homologs of gene ptz showing a global identity of only around $57 \% \mathrm{nt} / 47 \%$ aa between them (Figure 2, Supplementary Figure S2). As occurs in diverse strains of $P$. syringae pvs. nerii and savastanoi (Caponero et al., 1995; Ramos et al., 2012), some of the $p t z$ and $i d i$ homologs were located in plasmids in $P$. meliae and $P$. syringae pvs. cerasicola, myricae, and photiniae (Supplementary Figure S3). Using blastp, blastn, and tblastn, we did not find homologs of genes $p t z$ and $i d i$ in any other genome from bacteria of the P. syringae complex.

An analysis of the available genomes in the NCBI (March 2020) showed that genes $p t z$ and $i d i$ are located in the same contig in P. syringae pv. myricae ICMP 11510, separated by a putative class $B$ radical SAM methyltransferase gene and an insertion of ISPsy46, and that this arrangement is conserved in other $P$. syringae pv. myricae strains. The methyltransferase and the $i d i$ genes were highly similar and syntenic in pPsv48C, from Psv NCPPB 3335. Additionally, in pPsv48C the last $27 \mathrm{nt}$ of $p t z$ are found preceding the methyltransferase gene, whereas the remaining $p t z$ gene is missing and replaced by a fragment of the mobile element ISPa26 (Supplementary Figure S4).

Together, these results show that the possession of genes $p t z$ and $i d i$ by plant pathogenic bacteria is not strictly associated with the induction of tumors in the host plant, that both genes were linked when first acquired by PG3 (genomospecies 2), and that a different allele of $p t z$ has been independently acquired by the Psv clade (as shown in bold in Figure 2). Noticeably, the ptz gene from strain NCPPB 3335 is included in a putative genomic island in plasmid A (Bardaji et al., 2011), which might have favored its distribution among the bacterial population.

\section{Generation of a Plasmidless Derivative of NCPPB 3335}

Strain NCPPB 3335 contains three native plasmids (A, B, and C) carrying several genes of relevance for the interaction with the plant host (Figure 3A) (Bardaji et al., 2017; Castañeda-Ojeda et al., 2017a; Castañeda-Ojeda et al., 2017b). We therefore wanted to construct a derivative of NCPPB 3335 cured of the three native plasmids to analyze their possible collective contribution to virulence and as a tool for future genetic analyses. For clarity, from now on we will designate bacterial strains with the letter $\Delta$ and the plasmid(s) or gene(s) that they are missing, with their collection names shown in Supplementary Table S1. 


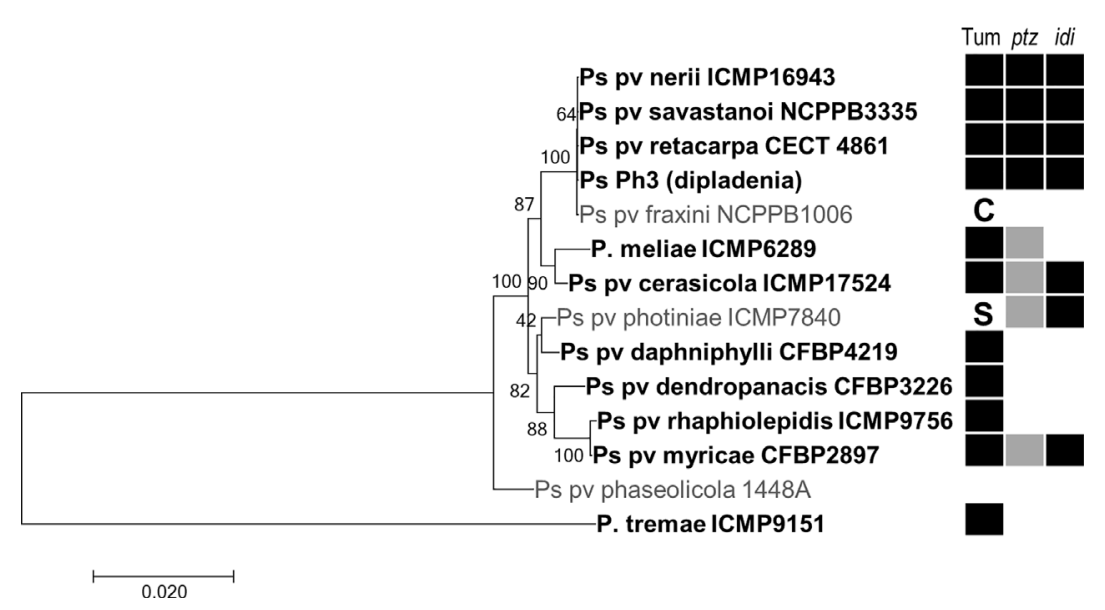

FIGURE 2 | Distribution of cytokinin biosynthesis genes in selected bacteria of the $P$. syringae complex. ML tree based on the concatenated nt sequence of 10 housekeeping genes of representative strains of each pathovar, inferred using the Tamura-Nei model with a discrete gamma distribution with five categories using MEGA 7. Nodes indicate bootstrap percentages over 200 replicas, and branch lengths are the number of substitutions per site. Bacteria reported to induce tumors are indicated in bold and with a black square (Tum); other symptoms: C, cankers and wart-like excrescences; S, leaf spots and blights. Filled and blank squares indicated presence or absence, respectively, of the gene in each pathovar, as assessed by blast and/or PCR. The two colors for gene ptz indicate the two distinct homologs found.

We constructed a derivative of strain $\triangle \mathrm{AB}$ containing plasmid C tagged with Tn5-GDYN1 (Figure 3), which carries a sacB gene conferring lethality in the presence of $5 \%$ sucrose. To facilitate loss of plasmid C, its toxin-antitoxin systems were functionally neutralized by overexpressing the corresponding antitoxins from plasmid pRK3C $\left(\mathrm{Tc}^{\mathrm{R}}\right)$ (Supplementary Table S1).

The examination of the plasmid profile of more than 700 sucrose resistant $\left(\operatorname{suc}^{\mathrm{R}}\right)$ clones revealed that all lacked the band corresponding to plasmid $\mathrm{C}$ and contained a smaller plasmid of 4-15 kb. PCR, and DNA hybridization showed that these small plasmids were all deletion derivatives of pPsv $48 \mathrm{C}$, originating by anomalous, one-ended transposition events of IS801 (data not shown). Several suc ${ }^{R}$ clones were propagated six times serially on LB without selection. A colony out of $>300$ tested was $\mathrm{Tc}^{\mathrm{s}}$, and its plasmid profile indicated the loss of both pRK3C and the pPsv48C deleted derivative (Figure 3B); this clone was retained and designated $\triangle \mathrm{ABC}$. The genome sequence of $\triangle \mathrm{ABC}$ confirmed that it was free of the three plasmids and contained no apparent reorganizations or major indels, as assessed by a genome comparison with strain NCPPB 3335 using WebACT (data not shown).

The same procedure as above was followed to obtain a derivative of NCPPB 3335, cured of only pPsv48C::Tn5GDYN1. We were unable to entirely cure this plasmid but
A

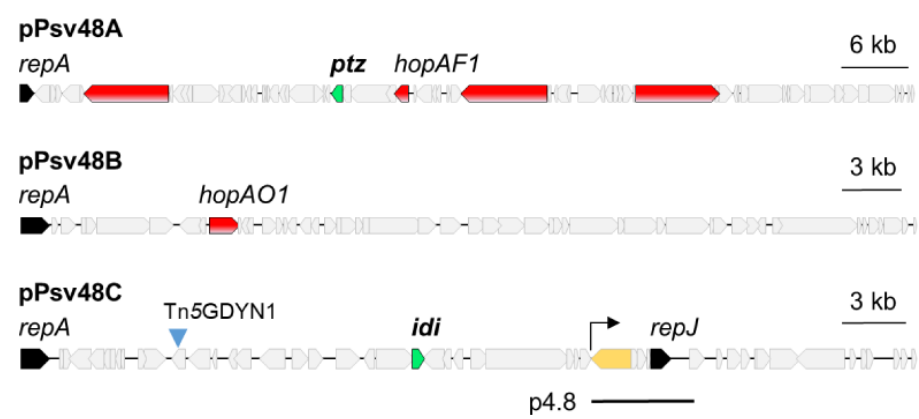

B

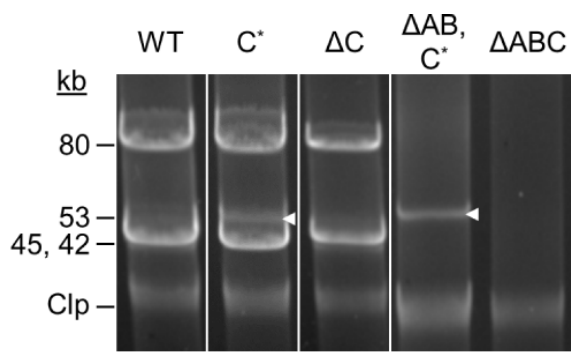

FIGURE 3 | Plasmid profiles of plasmid-cured derivatives of Pseudomonas syringae pv. savastanoi NCPPB 3335. (A) Map of the three virulence plasmids of Ps pv. savastanoi NCPPB 3335, showing in red, two type III effector genes (hopAF1 and hopAO1) and three putative virulence genes; in green, genes coding for cytokinin biosynthesis enzymes; in black, genes for replication initiator proteins; and in yellow, the only copy of IS801 in pPsv48C, with the arrow indicating the direction of one-ended transpositions. The black line labeled as p4.8 indicates the position and extent of the deleted derivative of pPsv48C present in strain $\Delta \mathrm{C}$. (B) Uncut plasmids were separated by electrophoresis in agarose gels from the strains shown. Strains: WT, wild type NCPPB 3335 ; letters after the $\Delta$ symbol indicate the plasmid(s) missing in each strain; C*, pPsv48C::Tn5-GDYN1, indicated by white arrowheads. Clp, chromosome and linearized plasmids. 
generated a strain containing a $4.8 \mathrm{~kb}$ plasmid (coordinates 27019-31852 of FR820587), resulting from a major deletion event of pPsv48C and lacking pRK3C (plasmid p4.8; Figure 3). We will refer to this strain as $\Delta \mathrm{C}$ because this $4.8 \mathrm{~kb}$ deletion plasmid only contains an IS801, a hypothetical protein and replicon RepJ, carrying no known or putative virulence genes.

In summary, we were able to evict a highly stable plasmid tagged with a counterselection marker (gene $s a c B$ ), by selection for survival in sucrose combined with functional inactivation of toxin-antitoxin systems. Given the relevance of native plasmids in plant pathogenic bacteria, the high stability provided by toxinantitoxin systems (Bardaji et al., 2019) and their widespread presence in native plasmids (Vivian et al., 2001; Sundin, 2007; Shidore and Triplett, 2017; Bardaji et al., 2019), our methodology shall be of general applicability for plasmid curing for genetic and functional studies.

\section{Plasmid pPsv48C From NCPPB 3335 Is Essential for Tumor Formation in Olive}

Inoculation of plasmid-cured strains allows for a rapid evaluation of the joint contribution of a large number of genes to virulence. In strain NCPPB 3335, plasmids A, B, and C contain diverse putative virulence genes, including two type III secretion system effector (T3E) genes and genes ptz (plasmid A) and idi (plasmid C) (Figure 3A; Bardaji et al., 2011). Our previous results indicated that plasmid A was necessary for tumor formation in olive (Bardaji et al., 2011), and we evaluated here the potential individual contribution of the other two plasmids.

All strains developed similar symptoms in inoculated oneyear-old and micropropagated olive plants (Figure 4). As described, the wild-type strain NCPPB 3335 induced typical tumors, whereas strain $\triangle \mathrm{AB}$ induced severely reduced tumors (Rodríguez-Moreno et al., 2009; Bardaji et al., 2011; CastañedaOjeda et al., 2017b). Strain $\Delta \mathrm{B}$ induced tumors of a size and weight between those produced by the wild-type strain (strain $\mathrm{NCPPB} 3335$ ) and $\triangle \mathrm{AB}$. Additionally, tumors produced by this strain in micropropagated plants were of wild-type size but slightly necrotic. These phenotypes agree with previous results, demonstrating that loss of the T3E gene hopAO1 located in plasmid B leads to smaller and necrotic tumors (CastañedaOjeda et al., 2017b), and suggest that plasmid B does not contain other relevant virulence genes. Strains $\Delta \mathrm{C}$ and $\Delta \mathrm{BC}$ both lack plasmid $\mathrm{C}$ and produced tumors with a further significant weight reduction over the previous strains. Strain $\triangle \mathrm{ABC}$, lacking the three plasmids, produced symptoms that were indistinguishable from those produced by strains lacking plasmid C.

Additionally, all the strains used in inoculation experiments were tagged with the green-fluorescent protein (GFP) using plasmid pLRM1-GFP (Rodríguez-Moreno et al., 2009). This suggests that all wild type and mutant strains are able to efficiently colonize the tumors (Figure 4). The patchy fluorescence pattern of some of the plasmid-cured strains is difficult to interpret and could be due to a restricted distribution of bacterial populations or to the already described dynamic evolution of fluorescence (Rodríguez-Moreno et al., 2009).

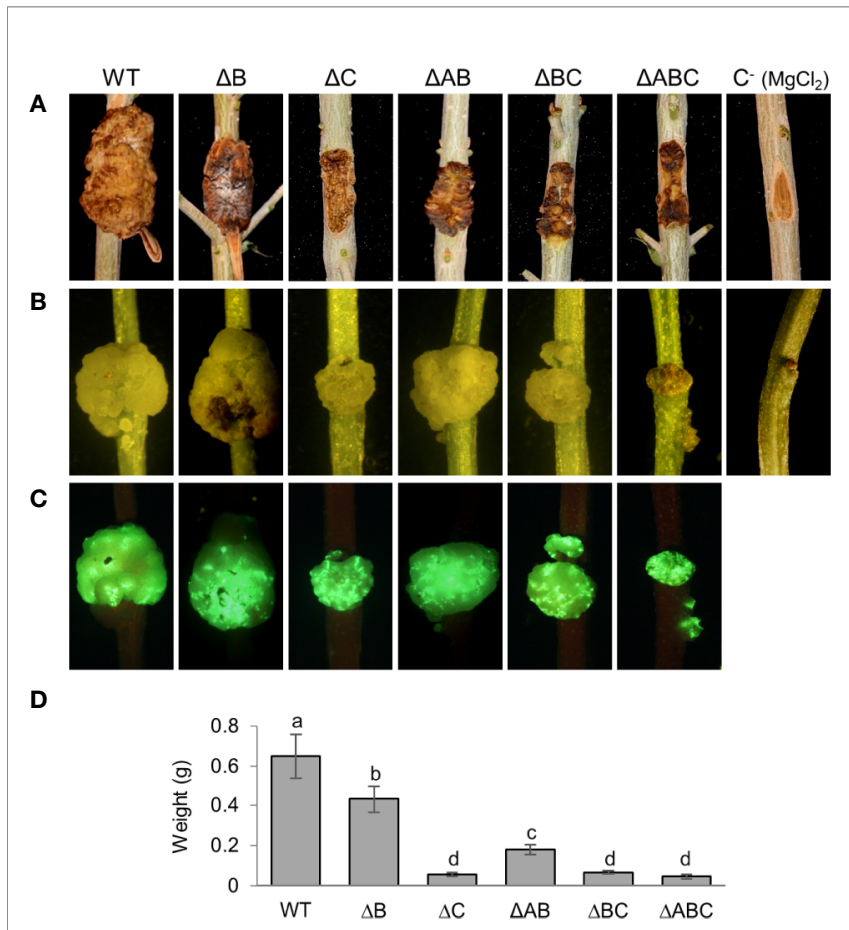

FIGURE 4 | Symptoms induced in olive plants by NCPPB 3335 derivatives strains cured of native plasmids. (A) Knots developed in one-year-old lignified olive plantlets 90 days post-inoculation (dpi) by the indicated strains. (B) Knots developed in micropropagated olive plantlets by the indicated GFPtagged strains at $28 \mathrm{dpi}$ and (C) complementary epifluorescence microscopy images of knots. (D) Quantification of knot weight generated by the indicated strain. Error bars represent the standard deviation from the average weight of a minimum of three knots. The same letters indicate differences that were not significant $(\alpha=0.05)$, using a two-way ANOVA followed by the Duncan's test. Experiments were carried out in triplicate, with three inoculated plants per strain and experiment. Strains: WT, NCPPB 3335; letters after the $\Delta$ symbol indicate the plasmid(s) missing in each strain; $\mathrm{C}-$, negative control inoculated with $\mathrm{MgCl}_{2}$

In summary, these results indicate that strain NCPPB 3335 contains three functional virulence plasmids that are clearly essential for the elicitation of full symptoms in its plant host.

\section{Genes ptz and idi Are Essential to Produce Tumors in Olive Plants}

Since manipulation of the levels of phytohormones is central in the interaction with plants of diverse phytopathogens ( $\mathrm{Ma}$ and Ma, 2016), we hypothesized that the phenotypes displayed by strains devoid of plasmids A and/or C could be due, at least in part, to the lack of genes ptz (plasmid A) and idi (plasmid C), which are likely involved in the biosynthesis of CKs. To address this hypothesis, we constructed single-knockout $p t z(\Delta \mathrm{ptz})$ and $i d i$ ( $\Delta$ idi) mutants, and a double-knockout mutant $p t z i d i(\Delta \mathrm{ptz}-$ idi) (Supplementary Table S1). For complementation analyses, we constructed three vectors containing genes $p t z$ and $i d i$ cloned individually or together, and expressed from their own promoters. In the plasmid containing only gene $p t z$, this gene was also expressed from the constitutive $\mathrm{P}_{\text {lac }}$ promoter of the 
vector. Gene idi is the second CDS of a possible operon including a putative methyltransferase gene (PSPSV_C0023); we therefore constructed complementation plasmids containing only gene idi or both, PSPSV_C0023 and idi. In the first case, gene idi was cloned plus a $578 \mathrm{nt}$ fragment upstream of its start codon that contains two putative promoters, as predicted by the BPROM software (Supplementary Figure S1); importantly, the fragment was cloned behind a strong transcriptional terminator, ensuring that transcription must originate from within the insert.

We evaluated the contribution of genes $p t z$ and idi for virulence in both lignified one year-old olive plants (Figure 5) and micropropagated olive plants (Supplementary Figure S5), the latter routinely used for virulence assays because they show a higher susceptibility to olive knot disease (Rodríguez-Moreno et al., 2008). Plants inoculated with the wild-type strain NCPPB 3335 developed typical tumors in both plant systems, which were of $434 \pm 91$ and $24 \pm 2 \mathrm{~mm}^{3}$ average volume in lignified and micropropagated plants, respectively, similar to previous results (Aragón et al., 2014). In contrast, strain $\triangle \mathrm{ABC}$ and mutants $\Delta \mathrm{ptz}$, $\Delta$ idi and $\Delta$ ptz-idi induced barely visible tumors that were significantly smaller than those elicited by the wild-type strain, with mean volumes of 6-85 and 7-11 $\mathrm{mm}^{3}$ in lignified (Figure 5) and micropropagated plants (Supplementary Figure S5), respectively.

In micropropagated olive plants, complementation of tumor volume was only partial for all mutants (Supplementary Figure S5). However, in lignified plants the cloned genes $p t z$ and idi completely reversed the phenotype of the individual mutants. Differences in complementation of mutants using both types of plants have already been observed for other virulence factors (Aragón et al., 2015a; Aragón et al., 2015b; Caballo-Ponce et al., 2017b) and could be due to a different hormonal regulation between micropropagated and lignified plants. Although the low virulence phenotype of strain $\Delta$ idi was also fully complemented by the vector containing the fragment with genes PSPSV_C0023 and idi (Supplementary Figure S1 and data not shown), the observed complementation with gene idi cloned by itself indicates that this gene is immediately preceded by a functional promoter and likely not included in an operon. In lignified plants, complementation of the double mutant $\Delta$ ptz-idi and the plasmidless strain $\triangle \mathrm{ABC}$ with the plasmid encoding both $p t z$ and $i d i$ was also only partial (Figure 5). This could be due to a lower level of expression of $p t z$ when it was cloned with gene idi than when it was cloned singly, because in this last case it was also transcribed from the constitutive $\mathrm{P}_{\text {lac }}$ promoter from the vector. Additionally, the lower virulence of the complemented strain $\triangle \mathrm{ABC}$ could be due to the lack of other plasmid-borne genes that might contribute to the tumorigenesis. In fact, tumors developed in micropropagated plants infected with strain $\triangle \mathrm{ABC}$ or its complemented derivative were necrotic (Supplementary Figure S5), likely because they lack the T3E gene hopAO1 (Castañeda-Ojeda et al., 2017b).

In both plants systems, total bacterial populations in tumors were significantly higher for the wild-type strain than for strain $\triangle \mathrm{ABC}$ or for the $\Delta \mathrm{ptz}$ and $\Delta \mathrm{idi}$ mutants (Figure 5B, Supplementary Figure S5). In most cases, total bacterial counts were fully recovered by complementation, with the exception of the double $\Delta$ ptz-idi mutant in micropropagated olive plants (Supplementary Figure S5)
A

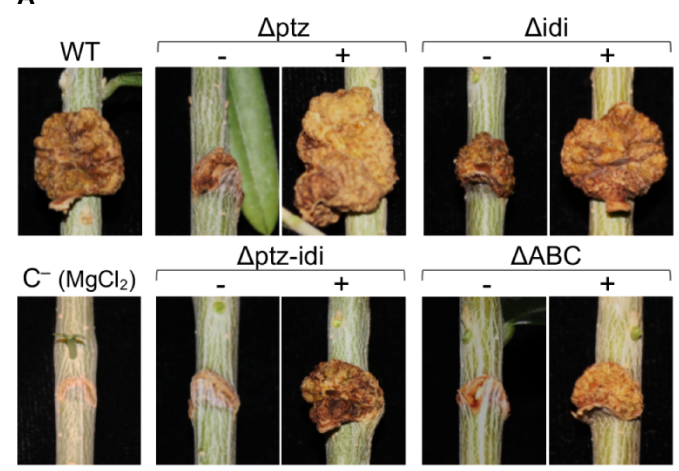

B
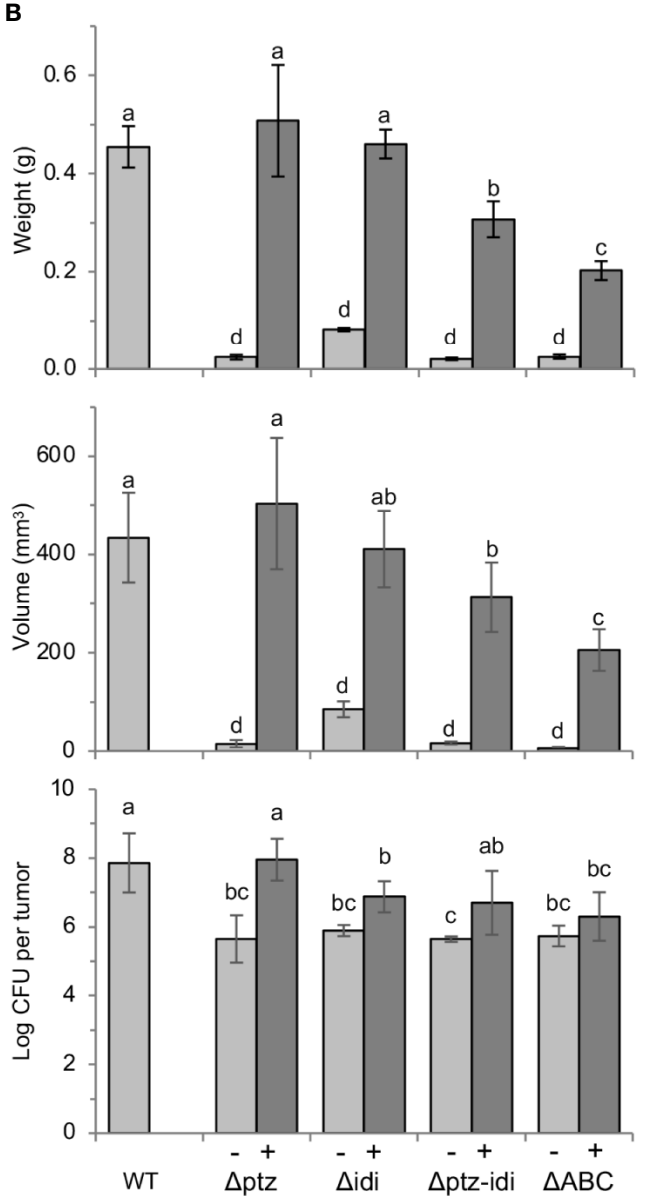

FIGURE 5 | Genes ptz and idi, coding for enzymes for cytokinin biosynthesis, are essential for the induction of symptoms in one-year-old olive plants. (A), Symptoms induced in lignified olive plantlets 90 days after inoculation. (B), Average weight, volume, and bacterial population of at least three tumors induced by the indicated strains, with bars indicating standard deviation; different letters above bars indicate means that are significantly different according to a two-way ANOVA ( $P \leq 0.05)$ followed by the Duncan's test. WT, strain NCPPB 3335. Symbols (-) and (+) indicate without or with complementation, respectively, with the deleted gene(s) cloned in a broad host-range vector. Results represent the mean of at least two experiments, each with three olive plants inoculated per strain. 
and strain $\triangle \mathrm{ABC}$ and the $\triangle \mathrm{idi}$ mutant in lignified plants (Figure 5), which were recovered only partially. The population densities of the strains were also calculated per gram of plant tissue, in order to analyse whether the mutant strains multiplied successfully in olive plants but failed to produce knots. However, the number of cfu/g of plant tissue reached by all mutant strains was approximately one order of magnitude lower than that of the wild-type strain (Supplementary Figure S6), further demonstrating that lack of $p t z$ and $i d i$ affects the ability of the strains to multiply and/or survive in olive tissues.

Together, these results unequivocally show that both $p t z$ and $i d i$ are individually essential for the development of tumors in olive by Psv NCPPB 3335. Nevertheless, their contribution to virulence might be at least partially additive because the double mutant produced somewhat smaller tumors than either single mutant.

\section{Gene ptz Is Essential for the Biosynthesis of Cytokinins, but Not Gene idi}

Cultures filtrate from the wild-type strain NCPPB 3335 contained iP, iPR, DHZ, DHZR, tZ and tZR, as well as their monophosphate precursors and glycosylated forms of $\mathrm{tZ}$ and DHZ (Figure 6, Supplementary Table S3). From these, the most active form $t Z$ and its riboside $t Z R$ were the most abundant CKs. Likewise, and adding to the variability in the CKs spectrum produced by different Psv strains, we also detected minute amounts of cis-zeatin (cZ) and substituted forms in culture filtrates from strain NCPPB 3335 (Supplementary Table S3).

Culture filtrates from strains lacking plasmid A or those with the inactivated $p t z$ gene did not produce $\mathrm{tZ}$ or $\mathrm{DHZ}$ or their precursors, but still produced significant amounts of iP (Figure 6, Supplementary Table S3). In agreement with this, mutants of Psv lacking plasmids carrying gene $p t z$ have been previously described to still synthesize trace amounts of CKs and/or similar amounts of iP to their corresponding wild-type strain (MacDonald et al., 1986; Iacobellis et al., 1994). Conversely, strains lacking gene idi produced significantly higher amounts of $\mathrm{tZ}$ and similar amounts of the other CKs to the wild-type strain. Additionally, all mutants produced similar amounts of cZ CKs to strain NCPPB 3335. Complementation of site-directed mutants restored the ability to synthesize CKs (Figure 6), although to higher levels than in the wild-type strain. This is probably due to the genes being cloned in a plasmid, leading to a higher gene copy number and a likely higher gene expression. Additionally, expression of gene ptz cloned by itself is also driven by the constitutive $P_{\text {lac }}$ promoter from the vector. Nevertheless, $\mathrm{tZ}$ was in all cases still the most abundant CK in culture filtrates. Finally, the patterns of CKs found in filtrates from strains $\Delta \mathrm{C}$ and $\Delta \mathrm{idi}$ were essentially identical, as well as with the pairs $\Delta \mathrm{AB} / \Delta \mathrm{ptz}$ and $\Delta \mathrm{ABC} / \Delta \mathrm{ptz}-$ idi. This suggests that these plasmids do not contain other genes that might be involved in the biosynthesis of CKs.

Together, these results indicate that gene $p t z$, but not gene $i d i$, is essential for the biosynthesis of high amounts of trans-zeatin, isopentenyladenine and dihydrozeatin CKs and their substituted forms. In turn, the activity of gene $i d i$ influences the relative amounts of $\mathrm{tZ}$ in the CK cell pool.

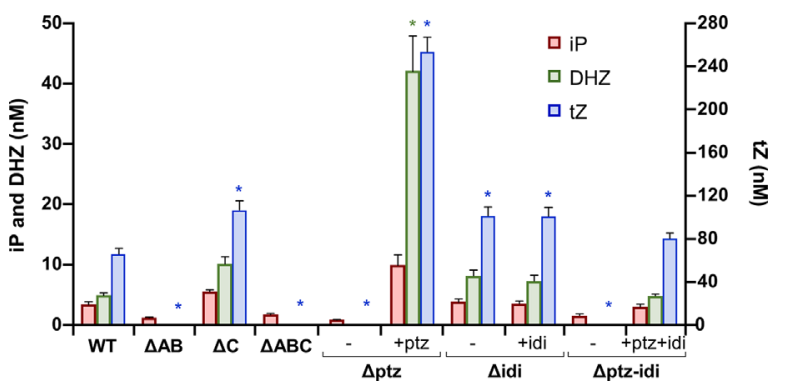

FIGURE 6 | Cytokinins produced in minimal medium by Pseudomonas syringae pv. savastanoi NCPPB 3335 and derivative mutants. WT, strain NCPPB 3335; letter $\Delta$ indicates the plasmid(s) or gene(s) missing in each mutant strain derived from NCPPB 3335; symbols (-) and (+) indicate without or with complementation, respectively, with genes ptz and/or idi cloned in a broad host-range vector. Bars indicate $\mathrm{nM}$ concentrations of each cytokinin, with trans-zeatin (tZ) values to the right, and isopentenyladenine (iP) and dihydrozeatin $(\mathrm{DHZ})$ values to the left. Results represent the average of three separate cultures, with two replicas each, and the standard error. Asterisks indicate significant differences from WT within each type of cytokinin $(\alpha=$ 0.05), using a two-way ANOVA followed by the Duncan's test.

\section{DISCUSSION}

Genes ptz and idi code for enzymes of the CK biosynthesis pathway, and here we show that they are both essential for the induction of full symptoms in olive plants by $P$. syringae pv. savastanoi NCPPB 3335 and for reaching high in planta bacterial populations. The use of plasmid-cured strains also showed that, although containing genes contributing to virulence (Bardaji et al., 2011; Castañeda-Ojeda et al., 2017a; Castañeda-Ojeda et al., 2017b), its three native plasmids do not contain any other gene(s) that are essential for CKs biosynthesis and tumorigenesis. Additionally, the wild-type strain NCPPB 3335 and its $p t z$, $i d i$, and $p t z-i d i$ mutants produced similar amounts of IAA under the same conditions used to quantify CKs (data not shown), suggesting that the observed phenotypes are not due to changes in auxin production. The scientific literature has largely assumed that the production of CKs contributes to virulence by Psv, mostly because the occurrence of large deletions involving gene $p t z$ or curing of plasmids containing this gene lead to a reduced virulence (MacDonald et al., 1986; Iacobellis et al., 1994; Bardaji et al., 2011). However, native plasmids from the $P$. syringae complex usually carry a large diversity of genes required for pathogenicity or full virulence, such as T3E genes (Jackson et al., 1999; Vivian et al., 2001; Sundin, 2007; Bardaji et al., 2011). Therefore, direct proof of the involvement of gene $p t z$ in, or the requirement of CKs for, virulence was lacking.

As previously reported for other Psv strains (Surico et al., 1985b; MacDonald et al., 1986; Powell and Morris, 1986; Iacobellis et al., 1994; Cinelli et al., 2014), NCPPB 3335 produces diverse CKs in vitro, of which $\mathrm{tZ}$ was by far the most abundant. Unlike previous reports with other strains, we were also able to detect $\mathrm{CZ}$ and substituted forms in cultures of NCPPB 3335; it is not known if this is a peculiarity of this strain or if it 
could be a more general feature. Free-base natural CKs, such as tZ, iP, and DHZ, have been shown to exhibit biological activity and are regarded as the active forms, whereas other modified forms of these CKs as well as $\mathrm{CZ}$ are considered to have at most a low level of activity (Sakakibara, 2010). Using site-directed mutagenesis, we demonstrate that gene $p t z$ is essential for the biosynthesis of high amounts of $\mathrm{tZ}, \mathrm{iP}$, and DHZ in culture; thus, it is feasible that trans-zeatin and/or its modified forms are involved in tumorigenesis in planta. Likewise, the $\mathrm{tZ}$ synthesizing gene from Agrobacterium tumefaciens, its CK products, or both, participate in the regulation of diverse virulence factors and are also needed for full tumorigenesis potential and in planta bacterial growth (Hwang et al., 2013).

Mutants lacking gene $i d i$ were still able to synthesize the same spectrum of CKs as the wild type (Figure 6, Supplementary Table S2), which agrees with previous results, showing that expression of $p t z$ from Psv in E. coli was sufficient to produce at least certain CKs (MacDonald et al., 1986; Powell and Morris, 1986). However, the $i d i$ mutant and the strain lacking plasmid $C$ $(\Delta \mathrm{C})$ produce significantly higher amounts of $\mathrm{tZ}$ than the wildtype strain; it is possible that this could be due to alterations in the concentration of the CKs precursors DMAPP and/or HMBDP, originating from the lack of the idi gene (Figure 1). Nevertheless, Ptz from NCPPB 3335 is closely related to the two isopentenyl transferases of Agrobacterium tumefaciens, coded by genes tmr and tzs (Powell and Morris, 1986), and Tmr uses HMBDP preferentially as a substrate (Sakakibara, 2006). Therefore, it is likely that Ptz also preferentially uses HMBDP. If this were the case, a mutation in idi would not necessarily impact the generation of adequate substrates for Ptz (Figure 1). The higher amount of $\mathrm{t} Z$ found in the idi mutants could then suggest that, under natural conditions, the activity of gene idi and/or its product leads to a reduction in the biosynthesis of $\mathrm{tZ}$ and DHZ in the wild-type strain NCPPB 3335, perhaps by altering the amount of substrates available in the cell. Independently of the mechanism involved, it is likely that idi might contribute to ensure a correct balance of the different CKs in planta, or to promote the synthesis of adequate substituted forms, to promote tumorigenesis. Thus, it could be possible that the inability of strains $\Delta \mathrm{idi}$ and $\Delta \mathrm{C}$ to induce tumors in olive plants (Figure 5, Supplementary Figure S5) is a consequence of their altered levels of $\mathrm{tZ}$, compared to those of the wild-type strain (Figure 6). Additionally, it would be worth investigating possible changes in the olive immune response towards the $p t z$ and idi mutants because it is well-established that CKs regulate plant defense responses in a dosage-dependent manner (Ma and Ma, 2016; Spallek et al., 2018).

The lack of genes $p t z$ and/or idi also affected the ability of the strains to grow and survive in olive tissues (Figure 5, Supplementary Figure S5), suggesting that reduction of the total bacterial population in the host might also affects tumor size. Other authors have reported that $P$. syringae pv. nerii strains cured of plasmids encoding $p t z$ are able to multiply at a rate similar to the wild-type strain in oleander leaves (Iacobellis et al., 1994). Furthermore, P. savastanoi strains isolated from Myrtus lacking gene ptz and producing undetectable amounts of CKs successfully invaded the host tissues and moved systemically, apparently unaffected by host defenses, such as the synthesis of tannins and the lignin deposits around the inoculation sites (Schiff et al., 2019). Thus, the role of CKs in the ability of $P$. savastanoi to multiply and survive in plant tissues might be strain- and/or host-dependent and could be influenced by other virulence factors varying among strains (Moreno-Pérez et al., 2020). An attractive possibility is that genes involved in CKs biosynthesis in Psv, including idi, might be regulating the expression of other virulence genes, as has been shown for certain Psv virulence genes upon exogenous IAA treatment (Aragón et al., 2014).

Indoleacetic acid is synthesized by strains of the $P$. syringae complex through three different metabolic pathways and by different, unrelated sets of genes (Howden et al., 2009; Aragón et al., 2014; McClerklin et al., 2018). The biosynthesis of CKs by Psv appears to also be complex and depend on several genes. First, the cloned $p t z$ gene from a Psv strain allowed E. coli to synthesize $\mathrm{tZ}, \mathrm{iP}$ and iPR, but not ribosyl-1"-methylzeatin, which was synthesized by the parental Psv strain (MacDonald et al., 1986; Powell and Morris, 1986). Therefore, it is possible that an additional gene(s) different from $p t z$ is responsible in Psv strains for the production of methyl CKs derivatives. Incidentally, a differential distribution of this gene in the pathogen population could explain why certain Psv strains synthesize the methylated forms whereas other strains do not (MacDonald et al., 1986; Cinelli et al., 2014). It is tempting to speculate that the methyltransferase gene found adjacent to gene idi could participate in the methylation of CKs found in Psv (Surico et al., 1985a; Evidente et al., 1986; MacDonald et al., 1986), although it would be necessary to support this with adequate experimental evidence. Secondly, although gene $p t z$ is essential for the production of high amounts of CKs by strain NCPPB 3335 in culture, the $\Delta \mathrm{ptz}$ mutants still synthesized significant amounts of iP and traces of other CKs (Supplementary Table S2). This has also been reported for other Psv strains (MacDonald et al., 1986; Iacobellis et al., 1994), indicating that Psv must contain other gene(s) involved in the biosynthesis of CKs, although in such a concentration that likely does not allow them to induce tumors. This scenario would be similar to the biosynthesis of IAA by strains of the $P$. syringae complex. A large proportion of $P$. syringae strains produce small amounts of IAA that, at least in the case of Ps pv. tomato DC3000, contribute modestly to virulence, probably by helping to suppress plant defense responses (Glickmann et al., 1998; Ma and Ma, 2016; McClerklin et al., 2018). Additionally, some strains contain the iaaMH operon and are able to produce high amounts of IAA, which in certain cases allow the bacterium to induce tumors in the plant host (Glickmann et al., 1998; Aragón et al., 2014). It is thus conceivable that the ability to synthesize low amounts of CKs might be common in the $P$. syringae complex, perhaps participating in the suppression of plant defenses (Ma and $\mathrm{Ma}$, 2016; Spallek et al., 2018), whereas only a few pathovars will have the ability to synthesize high amounts of CKs by means of gene $p t z$ and to be tumorigenic. We have to stress that there are strains of diverse pathovars of the $P$. syringae complex that contain 
genes iaaMH, ptz and/or produce high amounts of IAA or CKs, but that do not induce tumors in their common plant hosts (Glickmann et al., 1998; Cinelli et al., 2014). These strains, therefore, might lack some of the numerous genes needed for tumorigenesis (such as genes for type III secretion system effectors, for $\mathrm{Na}^{+} / \mathrm{Ca}^{2+}$ exchange or for the metabolism of phenolics) or to not produce an adequate balance of phytohormones (Caballo-Ponce et al., 2017a; Moretti et al., 2019; Moreno-Pérez et al., 2020).

Genes $p t z$ and $i d i$ have a limited distribution among bacteria (Supplementary Figure S2), and their possession is not correlated with the colonization of woody hosts or with the induction of tumors. In particular, we found homologs in the genomes of only a few bacteria of the $P$. syringae complex (Figure 2), although all infecting woody plants and belonging to PG3 (genomospecies 2) (Gardan et al., 1999; Gomila et al., 2017). Remarkably, no homologs, or only for one of the genes, were found in the genomes of certain pathovars that elicit tumors, such as $P$. amygdali, $P$. meliae, $P$. syringae pvs. dendropanacis or rhaphiolepidis (Figure 2). Additionally, we found both genes $p t z$ and $i d i$ in the genomes of $P$. syringae pv. photiniae deposited in the NCBI, even though this pathovar produces leaf spots (Goto, 1983) and is not reported to induce tumors. These discrepancies might be due to one or more of these reasons: 1) that there is variability in the distribution of these genes among all the tumorigenic bacteria, being absent in a small proportion of strains, as occurs in pathovars nerii and savastanoi (Cinelli et al., 2014; Moreno-Pérez et al., 2020); in particular, the three genomes currently available for $P$. amygdali are for strain NCPPB 2607, which was shown to produce negligible amounts of CKs in culture (Iacobellis et al., 1990) and that might therefore naturally lack $p t z ; 2)$ that the genes remained in the non-assembled reads, which is possible given that these genes are often surrounded by repeated sequences and their exclusion from the assembly has already been reported for other draft genomes (Moreno-Pérez et al., 2020); 3) that the sequenced strain has been misidentified, which is somewhat common among sequenced strains of the $P$. syringae complex (Gomila et al., 2017) and likely has occurred with the P. tremae strain, which belongs to PG3 and should have clustered close to the other strains (Gardan et al., 1999; Gomila et al., 2017); 4) that CKs perform diverse functions contributing to bacterial fitness and not necessarily related to the elicitation of tumors (Spallek et al., 2018), perhaps explaining the presence of genes $p t z$ and $i d i$ in many non-tumorigenic bacteria (Supplementary Figure S2); and 5) that the contribution of $p t z$ and $i d i$ to tumor development could be fulfilled by the activity of other gene(s) in certain bacterial phytopathogens.

Genes $p t z$ and $i d i$ have a complex evolutionary history within P. syringae PG3 (genomospecies 2) that involves ptz being acquired at least twice during evolution. Genes ptz and idi appear to have evolved separately for a long time, as shown by their disparate phylogenies, before being linked and incorporated in bacteria from PG3 (Supplementary Figures S2 and S4). The tumorigenic bacteria of PG3 are all in a single phylogenetic clade of pathogens of woody hosts, and intermingled with other species and pathovars causing cankers or other types of diseases (Gomila et al., 2017; Dillon et al., 2019b). It is likely therefore, that the DNA fragment with the linked ptz and idi genes was acquired only once during evolution, but that one or both genes were lost numerous times. Evidence for the independent loss of $p t z$ and/or idi comes from their patchy distribution among diverse pathovars, including $P$. syringae pvs. nerii and savastanoi (Iacobellis et al., 1998; Cinelli et al., 2014; Moreno-Pérez et al., 2020). The DNA fragment containing the linked $p t z$ and $i d i$ is currently present in, at least, strains of $P$. syringae pv. myricae and carried by native plasmids (Figure 2, Supplementary Figure S3), which likely facilitated its acquisition. Afterwards, gene $p t z$ was lost and, concurrently or independently, bacteria of the Psv clade acquired a different homolog of $p t z$ (Figure 2). Definite proof that $p t z$ and $i d i$ were ancestrally linked comes from the conservation of the last $27 \mathrm{nt}$ of the ptz CDS in front of the gene preceding idi in Psv NCPPB 3335 (Supplementary Figure S4). Its acquisition by the Psv clade and by PG3 for a second time during evolution therefore supports the notion that gene $p t z$ plays a significant role in the pathogenesis of $P$. syringae pvs. nerii, retacarpa, and savastanoi with their plant hosts.

In summary, this work firmly establishes the direct role of gene $p t z$ and/or its products in the biosynthesis of CKs, as well as gene idi, for the induction of tumors on olive plants by Psv. We present evidence that genes $p t z$ and $i d i$ were acquired, physically linked, exclusively by bacteria from PG3 and have likely been repeatedly lost. Upon loss of $p t z$ during evolution, tumorigenic bacteria from the savastanoi clade acquired a divergent homolog of $p t z$. Our results also indicate the existence of alternative routes for the biosynthesis of $\mathrm{iP}$ and $\mathrm{cZ}$ that do not require genes $p t z$ or idi.

\section{DATA AVAILABILITY STATEMENT}

The genome sequence generated in this work is available at the NCBI (https://www.ncbi.nlm.nih.gov/bioproject/638121) with the BioProject ID PRJNA638121 and the genome assembly accession ASM1391112v1.

\section{AUTHOR CONTRIBUTIONS}

CR and JM planned and designed the research and analyzed and interpreted the data. MA and AP performed the experiments. $\mathrm{ND}, \mathrm{LU}$, and $\mathrm{ON}$ provided all the cytokinin analyses. MA, AP, $\mathrm{CR}$, and JM carried out bioinformatics analyses, designed and prepared Figures and Tables, and wrote the manuscript.

\section{FUNDING}

AP, CR, and JM were supported by grants FPU14/05551, AGL201782492-C2-1-R and AGL2017-82492-C2-2-R, respectively, from Ministerio de Ciencia, Innovación y Universidades (Spain), 
cofinanced by the Fondo Europeo de Desarrollo Regional (FEDER). $\mathrm{ND}$, LU, and ON were supported by grant CZ.02.1.01/0.0/0.0/ 16_019/0000827, within the program Research, Development and Education (OP RDE).

\section{ACKNOWLEDGMENTS}

We are grateful to I. Imbroda (Guzman Biotech, Alhaurín de la Torre, Málaga, Spain) for micropropagation of olive plants. We thank M. Vega (SCAI, UMA) and P. García (Área de Genética,

\section{REFERENCES}

Agrios, G. N. (2005). Plant pathology (San Diego, USA: Elsevier Academic Press). Antoniadi, I., Plackova, L., Simonovik, B., Dolezal, K., Turnbull, C., Ljung, K., et al. (2015). Cell-type-specific cytokinin distribution within the arabidopsis primary root apex. Plant Cell 27 (7), 1955-1967. doi: 10.1105/tpc.15.00176

Aragón, I. M., Pérez-Martínez, I., Moreno-Pérez, A., Cerezo, M., and Ramos, C. (2014). New insights into the role of indole-3-acetic acid in the virulence of Pseudomonas savastanoi pv. savastanoi. FEMS Microbiol. Lett. 356 (2), 184192. doi: $10.1111 / 1574-6968.12413$

Aragón, I. M., Pérez-Mendoza, D., Gallegos, M.-T., and Ramos, C. (2015a). The cdi-GMP phosphodiesterase BifA is involved in the virulence of bacteria from the Pseudomonas syringae complex. Mol. Plant Pathol. 16 (6), 604-615. doi: $10.1111 / \mathrm{mpp} .12218$

Aragón, I. M., Pérez-Mendoza, D., Moscoso, J. A., Faure, E., Guery, B., Gallegos, M. T., et al. (2015b). Diguanylate cyclase DgcP is involved in plant and human Pseudomonas spp. infections. Environ. Microbiol. 17 (11), 4332-4351. doi: $10.1111 / 1462-2920.12856$

Bardaji, L., Pérez-Martínez, I., Rodríguez-Moreno, L., Rodríguez-Palenzuela, P., Sundin, G. W., Ramos, C., et al. (2011). Sequence and role in virulence of the three plasmid complement of the model tumor-inducing bacterium Pseudomonas savastanoi pv. savastanoi NCPPB 3335. PloS One 6 (10), e25705. doi: 10.1371/journal.pone.0025705

Bardaji, L., Añorga, M., Ruiz-Masó, J. A., del Solar, G., and Murillo, J. (2017). Plasmid replicons from Pseudomonas are natural chimeras of functional, exchangeable modules. Front. Microbiol. 8, 190. doi: 10.3389/fmicb.2017.00190

Bardaji, L., Añorga, M., Echeverría, M., Ramos, C., and Murillo, J. (2019). The toxic guardians - multiple toxin-antitoxin systems provide stability, avoid deletions and maintain virulence genes of Pseudomonas syringae virulence plasmids. Mobile DNA 10 (1), 7. doi: 10.1186/s13100-019-0149-4

Bender, C. L., Alarcón-Chaidez, F., and Gross, D. C. (1999). Pseudomonas syringae phytotoxins: mode of action, regulation, and biosynthesis by peptide and polyketide synthetases. Microbiol. Mol. Biol. Rev. 63, 266-292. doi: 10.1128/ MMBR.63.2.266-292.1999

Caballo-Ponce, E., Murillo, J., Martínez-Gil, M., Moreno-Pérez, A., Pintado, A., and Ramos, C. (2017a). Knots untie: molecular determinants involved in knot formation induced by Pseudomonas savastanoi in woody hosts. Front. Plant Sci. 8, 1089. doi: 10.3389/fpls.2017.01089

Caballo-Ponce, E., van Dillewijn, P., Wittich, R. M., and Ramos, C. (2017b). WHOP, a genomic region associated with woody hosts in the Pseudomonas syringae complex contributes to the virulence and fitness of Pseudomonas savastanoi pv. savastanoi in olive plants. Mol. Plant-Microbe Interact. 30 (2), 113-126. doi: 10.1094/mpmi-11-16-0233-r

Caponero, A., Contesini, A. M., and Iacobellis, N. S. (1995). Population diversity of Pseudomonas syringae subsp. savastanoi on olive and oleander. Plant Pathol. 44 (5), 848-855. doi: 10.1111/j.1365-3059.1995.tb02744.x

Carver, T., Berriman, M., Tivey, A., Patel, C., Bohme, U., Barrell, B. G., et al. (2008). Artemis and ACT: viewing, annotating and comparing sequences stored in a relational database. Bioinformatics 24 (23), 2672-2676. doi: 10.1093/bioinformatics/btn529
UMA) for excellent assistance with the image analysis of the knot volumes and with preparation of media and solutions, respectively. We are indebted to $\mathrm{T}$. $\mathrm{H}$. Osinga for help with English language.

\section{SUPPLEMENTARY MATERIAL}

The Supplementary Material for this article can be found online at: https://www.frontiersin.org/articles/10.3389/fpls.2020.01294/ full\#supplementary-material
Castañeda-Ojeda, M. P., López-Solanilla, E., and Ramos, C. (2017a). Differential modulation of plant immune responses by diverse members of the Pseudomonas savastanoi pv. savastanoi HopAF type III effector family. Mol. Plant Pathol. 18 (5), 625-634. doi: 10.1111/mpp.12420

Castañeda-Ojeda, M. P., Moreno-Pérez, A., Ramos, C., and López-Solanilla, E. (2017b). Suppression of plant immune responses by the Pseudomonas savastanoi pv. savastanoi NCPPB 3335 type III effector tyrosine phosphatases HopAO1 and HopAO2. Front. Plant Sci. 8, 680. doi: 10.3389/fpls.2017.00680

Choi, K. H., Kumar, A., and Schweizer, H. P. (2006). A 10-min method for preparation of highly electrocompetent Pseudomonas aeruginosa cells: Application for DNA fragment transfer between chromosomes and plasmid transformation. J. Microbiol. Methods 64, 391-397. doi: 10.1016/j.mimet.2005.06.001

Chojnacki, S., Cowley, A., Lee, J., Foix, A., and Lopez, R. (2017). Programmatic access to bioinformatics tools from EMBL-EBI update: 2017. Nucleic Acids Res. 45 (W1), W550-w553. doi: 10.1093/nar/gkx273

Cinelli, T., Marchi, G., Cimmino, A., Marongiu, R., Evidente, A., and Fiori, M. (2014). Heterogeneity of Pseudomonas savastanoi populations infecting Myrtus communis in Sardinia (Italy). Plant Pathol. 63 (2), 277-289. doi: $10.1111 /$ ppa.12096

Comai, L., and Kosuge, T. (1980). Involvement of plasmid deoxyribonucleic acid in indoleacetic acid synthesis in Pseudomonas savastanoi. J. Bacteriol. 143, 950-957. doi: 10.1128/JB.143.2.950-957.1980

Corpet, F. (1988). Multiple sequence alignment with hierarchical clustering. Nucleic Acids Res. 16 (22), 10881-10890. doi: 10.1093/nar/16.22.10881

Cunnac, S., Lindeberg, M., and Collmer, A. (2009). Pseudomonas syringae type III secretion system effectors: repertoires in search of functions. Curr. Opin. Microbiol. 12 (1), 53-60. doi: 10.1016/j.mib.2008.12.003

Denancé, N., Sánchez-Vallet, A., Goffner, D., and Molina, A. (2013). Disease resistance or growth: the role of plant hormones in balancing immune responses and fitness costs. Front. Plant Sci. 4, 155. doi: 10.3389/fpls.2013.00155

Dillon, M. M., Almeida, R. N. D., Laflamme, B., Martel, A., Weir, B. S., Desveaux, D., et al. (2019a). Molecular evolution of Pseudomonas syringae type III secreted effector proteins. Front. Plant Sci. 10, 418. doi: 10.3389/fpls.2019.00418

Dillon, M. M., Thakur, S., Almeida, R. N. D., Wang, P. W., Weir, B. S., and Guttman, D. S. (2019b). Recombination of ecologically and evolutionarily significant loci maintains genetic cohesion in the Pseudomonas syringae species complex. Genome Biol. 20 (1), 3. doi: 10.1186/s13059-018-1606-y

Dobrev, P. I., and Kaminek, M. (2002). Fast and efficient separation of cytokinins from auxin and abscisic acid and their purification using mixed-mode solidphase extraction. J. Chromatogr. A 950 (1-2), 21-29. doi: 10.1016/S0021-9673 (02)00024-9

Driver, J. A., and Kuniyuki, A. H. (1984). In vitro propagation of Paradox walnut rootstock. HortScience 19 (4), 507-509.

Evidente, A., Surico, G., Iacobellis, N. S., and Randazzo, G. (1986). 1'-methylzeatin, an additional cytokinin from Pseudomonas syringae pv. savastanoi. Phytochemistry 25 (2), 525-526. doi: 10.1016/S0031-9422(00)85515-6

Flores, M., Brom, S., Stepkowski, T., Girard, M. L., Dávila, G., Romero, D., et al. (1993). Gene amplification in Rhizobium: identification and in vivo cloning of discrete amplifiable DNA regions (amplicons) from Rhizobium leguminosarum biovar phaseoli. Proc. Natl. Acad. Sci. 90, 4932-4936. doi: 10.1073/pnas.90.11.4932 
Gardan, L., Shafik, H., Belouin, S., Broch, R., Grimont, F., and Grimont, P. A. D. (1999). DNA relatedness among the pathovars of Pseudomonas syringae and description of Pseudomonas tremae sp. nov. and Pseudomonas cannabina sp. nov. (ex Sutic and Dowson 1959). Int. J. Syst. Bacteriol. 49, 469-478. doi: 10.1099/00207713-49-2-469

Glickmann, E., Gardan, L., Jacquet, S., Hussain, S., Elasri, M., Petit, A., et al. (1998). Auxin production is a common feature of most pathovars of Pseudomonas syringae. Mol. Plant-Microbe Interact. 11, 156-162. doi: 10.1094/ MPMI.1998.11.2.156

Gomila, M., Busquets, A., Mulet, M., García-Valdés, E., and Lalucat, J. (2017). Clarification of taxonomic status within the Pseudomonas syringae species group based on a phylogenomic analysis. Front. Microbiol. 8, 2422. doi: $10.3389 /$ fmicb. 2017.02422

Goto, M. (1983). Pseudomonas syringae pv. photiniae pv. nov., the causal agent of bacterial leaf spot of Photinia glabra Maxim. Ann. Phytopathol. Soc. Japan 49 (4), 457-462. doi: 10.3186/jjphytopath.49.457

Holmes, D. S., and Quigley, M. (1981). A rapid boiling method for the preparation of bacterial plasmids. Anal. Biochem. 114 (1), 193-197. doi: 10.1016/0003-2697 (81)90473-5

Hosni, T., Moretti, C., Devescovi, G., Suarez-Moreno, Z. R., Fatmi, M. B., Guarnaccia, C., et al. (2011). Sharing of quorum-sensing signals and role of interspecies communities in a bacterial plant disease. ISME J. 5 (12), 18571870. doi: 10.1038/ismej.2011.65

Howden, A. J. M., Rico, A., Mentlak, T., Miguet, L., and Preston, G. M. (2009). Pseudomonas syringae pv. syringae B728a hydrolyses indole-3-acetonitrile to the plant hormone indole-3-acetic acid. Mol. Plant Pathol. 10 (6), 857-865. doi: 10.1111/j.1364-3703.2009.00595.x

Hubbard, T. J., Aken, B. L., Ayling, S., Ballester, B., Beal, K., Bragin, E., et al. (2008). Ensembl 2009. Nucleic Acids Res. 37, D690 - D697. doi: 10.1093/nar/gkn828

Huot, B., Yao, J., Montgomery, B. L., and He, S. Y. (2014). Growth-defense tradeoffs in plants: a balancing act to optimize fitness. Mol. Plant 7 (8), 12671287. doi: $10.1093 / \mathrm{mp} / \mathrm{ssu} 049$

Hwang, H.-H., Yang, F.-J., Cheng, T.-F., Chen, Y.-C., Lee, Y.-L., Tsai, Y.-L., et al. (2013). The Tzs protein and exogenous cytokinin affect virulence gene expression and bacterial growth of Agrobacterium tumefaciens. Phytopathology 103 (9), 888-899. doi: 10.1094/phyto-01-13-0020-r

Iacobellis, N. S., Evidente, A., Surico, G., Sisto, A., and Gammaldi, G. (1990). Production of phytohormones by Pseudomonas amygdali and their role in the hyperplastic bacterial canker of almond. J. Phytopathol. 129 (3), 177-186. doi: 10.1111/j.1439-0434.1990.tb04583.x

Iacobellis, N. S., Sisto, A., Surico, G., Evidente, A., and DiMaio, E. (1994). Pathogenicity of Pseudomonas syringae subsp. savastanoi mutants defective in phytohormone production. J. Phytopathol. 140, 238-248. doi: 10.1111/ j.1439-0434.1994.tb04813.x

Iacobellis, N. S., Caponero, A., and Evidente, A. (1998). Characterization of Pseudomonas syringae ssp. savastanoi strains isolated from ash. Plant Pathol. 47 (1), 73-83. doi: 10.1046/j.1365-3059.1998.00202.x

Jackson, R. W., Athanassopoulos, E., Tsiamis, G., Mansfield, J. W., Sesma, A., Arnold, D. L., et al. (1999). Identification of a pathogenicity island, which contains genes for virulence and avirulence, on a large native plasmid in the bean pathogen Pseudomonas syringae pathovar phaseolicola. Proc. Natl. Acad. Sci. 96, 10875-10880. doi: 10.1073/pnas.96.19.10875

Kumar, S., Stecher, G., and Tamura, K. (2016). MEGA7: Molecular Evolutionary Genetics Analysis version 7.0 for bigger datasets. Mol. Biol. Evol. 33, 18701874. doi: 10.1093/molbev/msw054

Lamichhane, J. R., Varvaro, L., Parisi, L., Audergon, J.-M., and Morris, C. E. (2014). "Disease and frost damage of woody plants caused by Pseudomonas syringae: seeing the forest for the trees," in Advances in Agronomy. Ed. D. L. Sparks (San Diego, CA: Academic Press), 235-295.

Lamichhane, J. R., Messéan, A., and Morris, C. E. (2015). Insights into epidemiology and control of diseases of annual plants caused by the Pseudomonas syringae species complex. J. Gen. Plant Pathol. 81 (5), 331350. doi: 10.1007/s10327-015-0605-Z

Ma, K.-W., and Ma, W. (2016). Phytohormone pathways as targets of pathogens to facilitate infection. Plant Mol. Biol. 91 (6), 713-725. doi: 10.1007/s11103-0160452-0

MacDonald, E. M. S., Powell, G. K., Regier, D. A., Glass, N. L., Roberto, F., Kosuge, T., et al. (1986). Secretion of zeatin, ribosylzeatin, and ribosyl-1"'-methylzeatin by
Pseudomonas savastanoi: plasmid-coded cytokinin biosynthesis. Plant Physiol. 82 (3), 742-747. doi: 10.1104/pp.82.3.742

Marchi, G., Cinelli, T., and Surico, G. (2011). "A review on Pseudomonas savastanoi genetic traits involved in disease development and in symptom induction," in Olive Diseases and Disorders. Eds. L. Schena, G. E. Agosteo and S. O. Cacciola (Kerala, India: Transworld Research Network), 117-141.

Matas, I. M., Lambertsen, L., Rodríguez-Moreno, L., and Ramos, C. (2012). Identification of novel virulence genes and metabolic pathways required for full fitness of Pseudomonas savastanoi pv. savastanoi in olive (Olea europaea) knots. New Phytol. 196 (4), 1182-1196. doi: 10.1111/j.1469-8137.2012.04357.x

Matas, I. M., Castañeda-Ojeda, M. P., Aragón, I. M., Antúnez-Lamas, M., Murillo, J., Rodríguez-Palenzuela, P., et al. (2014). Translocation and functional analysis of Pseudomonas savastanoi pv. savastanoi NCPPB 3335 type III secretion system effectors reveals two novel effector families of the Pseudomonas syringae complex. Mol. Plant-Microbe Interact. 27 (5), 424-436. doi: 10.1094/mpmi-0713-0206-r

McClerklin, S. A., Lee, S. G., Harper, C. P., Nwumeh, R., Jez, J. M., and Kunkel, B. N. (2018). Indole-3-acetaldehyde dehydrogenase-dependent auxin synthesis contributes to virulence of Pseudomonas syringae strain DC3000. PloS Pathog. 14 (1), e1006811. doi: 10.1371/journal.ppat.1006811

Miller, J. H. (1992). A short course in bacterial genetics - A laboratory manual and handbook for Escherichia coli and related bacteria (Plainview, NY: Cold Spring Harbor Laboratory Press).

Moreno-Pérez, A., Pintado, A., Murillo, J., Caballo-Ponce, E., Tegli, S., Moretti, C., et al. (2020). Host range determinants of Pseudomonas savastanoi pathovars of woody hosts revealed by comparative genomics and cross-pathogenicity tests. Front. Plant Sci. 11, 973. doi: 10.3389/fpls.2020.00973

Moretti, C., Ferrante, P., Hosni, T., Valentini, F., D’Onghia, A., Fatmi, M. B., et al. (2008). "Characterization of Pseudomonas savastanoi pv. savastanoi strains collected from olive trees in different countries," in Pseudomonas syringae Pathovars and Related Pathogens-Identification, Epidemiology and Genomics. Eds. M. Fatmi, A. Collmer, N. S. Iacobellis, J. W. Mansfield, J. Murillo, N. W. Schaad and M. S. Ullrich (Dordrecht: Springer), 321-329.

Moretti, C., Trabalza, S., Granieri, L., Caballo-Ponce, E., Devescovi, G., Del Pino, A. M., et al. (2019). A Na ${ }^{+} / \mathrm{Ca}^{2+}$ exchanger of the olive pathogen Pseudomonas savastanoi pv. savastanoi is critical for its virulence. Mol. Plant Pathol. 20 (5), 716-730. doi: 10.1111/mpp.12787

Morris, R. O., Jameson, P. E., Laloue, M., and Morris, J. W. (1991). Rapid identification of cytokinins by an immunological method. Plant Physiol. 95 (4), 1156-1161. doi: 10.1104/pp.95.4.1156

Ogimi, C., Higuchi, H., and Takikawa, Y. (1988a). Bacterial gall disease of urajiroenoki (Trema orientalis Blume) caused by Pseudomonas syringae pv. tremae pv. nov. J. Japanese Forest. Soc. 70 (10), 441-446. doi: 10.11519/jjfs1953.70.10_441

Ogimi, C., Higuchi, H., and Takikawa, Y. (1988b). Bacterial gall disease of kakuremino (Dendropanax trifidus Mak.) caused by Pseudomonas syringae pv. dendropanacis pv. nov. Ann. Phytopathol. Soc. Japan 54 (3), 296-302. doi: $10.3186 /$ jjphytopath.54.296

Ogimi, C., Kubo, Y., Higuchi, H., and Takikawa, Y. (1990). Bacterial gall diseases of himeyuzuriha (Daphniphyllum teijsmanni Z.) caused by Pseudomonas syringae pv. daphniphylli pv. nov. J. Japanese Forest. Soc. 72 (1), 17-22. doi: 10.11519/jjfs1953.72.1_17

Ogimi, C., Kawano, C., Higuchi, H., and Takikawa, Y. (1992). Bacterial gall disease of sharinbai (Rhaphiolepis umbellata) caused by Pseudomonas syringae pv. rhaphiolepidis pv. nov. J. Japanese Forest. Soc. 74 (4), 308-313. doi: 10.11519/ jjfs1953.74.4_308

Ogimi, C. (1977). Studies on bacterial gall of chinaberry (Melia azedarach Lin.), caused by Pseudomonas meliae n. sp. Bull. Coll. Agric. Univ. Ryukyus 24, 497-556.

Penyalver, R., Garcia, A., Ferrer, A., Bertolini, E., Quesada, J. M., Salcedo, C. I., et al. (2006). Factors affecting Pseudomonas savastanoi pv. savastanoi plant inoculations and their use for evaluation of olive cultivar susceptibility. Phytopathology 96 (3), 313-319. doi: 10.1094/phyto-96-0313

Pérez-Martínez, I., Rodríguez-Moreno, L., Matas, I. M., and Ramos, C. (2007). Strain selection and improvement of gene transfer for genetic manipulation of Pseudomonas savastanoi isolated from olive knots. Res. Microbiol. 158 (1), 60 69. doi: 10.1016/j.resmic.2006.09.008

Pérez-Martínez, I., Zhao, Y., Murillo, J., Sundin, G. W., and Ramos, C. (2008). Global genomic analysis of Pseudomonas savastanoi pv. savastanoi plasmids. J. Bacteriol. 190, 625-635. doi: 10.1128/JB.01067-07 
Pérez-Martínez, I., Rodríguez-Moreno, L., Lambertsen, L., Matas, I. M., Murillo, J., Tegli, S., et al. (2010). Fate of a Pseudomonas savastanoi pv. savastanoi type III secretion system mutant in olive plants (Olea europaea L.). Appl. Environ. Microbiol. 76 (11), 3611-3619. doi: 10.1128/aem.00133-10

Powell, G. K., and Morris, R. O. (1986). Nucleotide sequence and expression of a Pseudomonas savastanoi cytokinin biosynthetic gene: homology with Agrobacterium tumefaciens tmr and tzs loci. Nucleic Acids Res. 14 (6), 2555-2565. doi: 10.1093/nar/ 14.6.2555

R Core Team (2017). R: A language and environment for statistical computing. R Foundation for Statistical Computing, Vienna, Austria. Available online at: https://www.R-project.org/.

Ramos, C., Matas, I. M., Bardaji, L., Aragón, I. M., and Murillo, J. (2012). Pseudomonas savastanoi pv. savastanoi: some like it knot. Mol. Plant Pathol. 13 (9), 998-1009. doi: 10.1111/j.1364-3703.2012.00816.x

Roberto, F., and Kosuge, T. (1987). "Phytohormone metabolism in Pseudomonas syringae subsp. savastanoi," in Molecular Biology of Plant Growth Control. Eds. E. W. Fox and M. Jacobs (NY: Alan R. Liss), 371-380.

Rodríguez-Moreno, L., Barceló-Muñoz, A., and Ramos, C. (2008). In vitro analysis of the interaction of Pseudomonas savastanoi pvs. savastanoi and nerii with micropropagated olive plants. Phytopathology 98 (7), 815-822. doi: 10.1094/PHYTO-98-7-0815

Rodríguez-Moreno, L., Jiménez, A. J., and Ramos, C. (2009). Endopathogenic lifestyle of Pseudomonas savastanoi pv. savastanoi in olive knots. Microb. Biotechnol. 2 (4), 476-488. doi: 10.1111/j.1751-7915.2009.00101.x

Sakakibara, H. (2006). Cytokinins: activity, biosynthesis, and translocation. Annu. Rev. Plant Biol. 57 (1), 431-449. doi: 10.1146/annurev.arplant.57.032905.105231

Sakakibara, H. (2010). "Cytokinin biosynthesis and metabolism," in Plant Hormones: Biosynthesis, Signal Transduction, Action!. Ed. P. J. Davies (Dordrecht: Springer Netherlands), 95-114.

Sambrook, J., Fritsch, E. F., and Maniatis, T. (1989). Molecular Cloning: a Laboratory Manual (Cold Spring Harbor, NY: Cold Spring Harbor Laboratory).

Schiff, S., Tani, C., Cimmino, A., Mandala, G., Cinelli, T., Evidente, A., et al. (2019). The colonization processes of Myrtus communis by strains of Pseudomonas savastanoi with a differential ability to produce phytohormones. Plant Pathol. 68 (6), 1109-1119. doi: 10.1111/ppa.13021

Sesma, A., Sundin, G. W., and Murillo, J. (2000). Phylogeny of the replication regions of pPT23A-like plasmids from Pseudomonas syringae. Microbiology 146, 2375-2384. doi: 10.1099/00221287-146-10-2375

Shidore, T., and Triplett, L. R. (2017). Toxin-antitoxin systems: implications for plant disease. Annu. Rev. Phytopathol. 55 (1), 161-179. doi: 10.1146/annurevphyto-080516-035559

Silverstone, S. E., Gilchrist, D. G., Bostock, R. M., and Kosuge, T. (1993). The 73-kb pIAA plasmid increases competitive fitness of Pseudomonas syringae subspecies savastanoi in oleander. Can. J. Microbiol. 39, 659-664. doi: 10.1139/m93-095

Sisto, A., Cipriani, M. G., and Morea, M. (2004). Knot formation caused by Pseudomonas syringae subsp. savastanoi on olive plants is hrp-dependent. Phytopathology 94 (5), 484-489. doi: 10.1094/phyto.2004.94.5.484
Solovyev, V., and Salamov, A. (2011). "Automatic annotation of microbial genomes and metagenomic sequences," in Metagenomics and its applications in agriculture, biomedicine and environmental studies. Ed. R. W. Li (Hauppauge, NY: Nova Science Publishers), 61-78.

Spallek, T., Gan, P., Kadota, Y., and Shirasu, K. (2018). Same tune, different songcytokinins as virulence factors in plant-pathogen interactions? Curr. Opin. Plant Biol. 44, 82-87. doi: 10.1016/j.pbi.2018.03.002

Sundin, G. W. (2007). Genomic insights into the contribution of phytopathogenic bacterial plasmids to the evolutionary history of their hosts. Annu. Rev. Phytopathol. 45, 129-151. doi: 10.1146/annurev.phyto.45.062806.094317

Surico, G., Sparapano, L., Lerario, P., Durbin, R. D., and Iacobellis, N. (1975). Cytokinin-like activity in extracts from culture filtrates of Pseudomonas savastanoi. Experientia 31 (8), 929-930. doi: 10.1007/BF02358857

Surico, G., Evidente, A., Iacobellis, N. S., and Randazzo, G. (1985a). A cytokinin from the culture filtrate of Pseudomonas syringae pv. savastanoi. Phytochemistry 24 (7), 1499-1502. doi: 10.1016/S0031-9422(00)81053-5

Surico, G., Iacobellis, N. S., and Sisto, S. (1985b). Studies on the role of indole-3acetic acid and cytokinins in the formation of knots on olive and oleander plants by Pseudomonas syringae pv. savastanoi. Physiol. Plant Pathol. 26, 309320. doi: 10.1016/0048-4059(85)90006-2

Untergasser, A., Cutcutache, I., Koressaar, T., Ye, J., Faircloth, B. C., Remm, M., et al. (2012). Primer3-new capabilities and interfaces. Nucleic Acids Res. 40 (15), e115. doi: 10.1093/nar/gks596

Vivian, A., Murillo, J., and Jackson, R. W. (2001). The role of plasmids in phytopathogenic bacteria: mobile arsenals? Microbiology 147 (Pt 4), 763-780. doi: 10.1099/00221287-147-4-763

Yamada, T., Palm, C. J., Brooks, B., and Kosuge, T. (1985). Nucleotide sequences of the Pseudomonas savastanoi indoleacetic acid genes show homology with Agrobacterium tumefaciens T-DNA. Proc. Natl. Acad. Sci. 82, 6522-6526. doi: $10.1073 /$ pnas.82.19.6522

Young, J. M. (2010). Taxonomy of Pseudomonas syringae. J. Plant Pathol. 92 (1), S5-S14. doi: 10.4454/jpp.v92i1sup.2501

Zhou, C., Yang, Y., and Jong, A. Y. (1990). Miniprep in ten minutes. BioTechniques 8, 172-173.

Conflict of Interest: The authors declare that the research was conducted in the absence of any commercial or financial relationships that could be construed as a potential conflict of interest.

Copyright (c) 2020 Añorga, Pintado, Ramos, De Diego, Ugena, Novák and Murillo. This is an open-access article distributed under the terms of the Creative Commons Attribution License (CC BY). The use, distribution or reproduction in other forums is permitted, provided the original author(s) and the copyright owner(s) are credited and that the original publication in this journal is cited, in accordance with accepted academic practice. No use, distribution or reproduction is permitted which does not comply with these terms. 